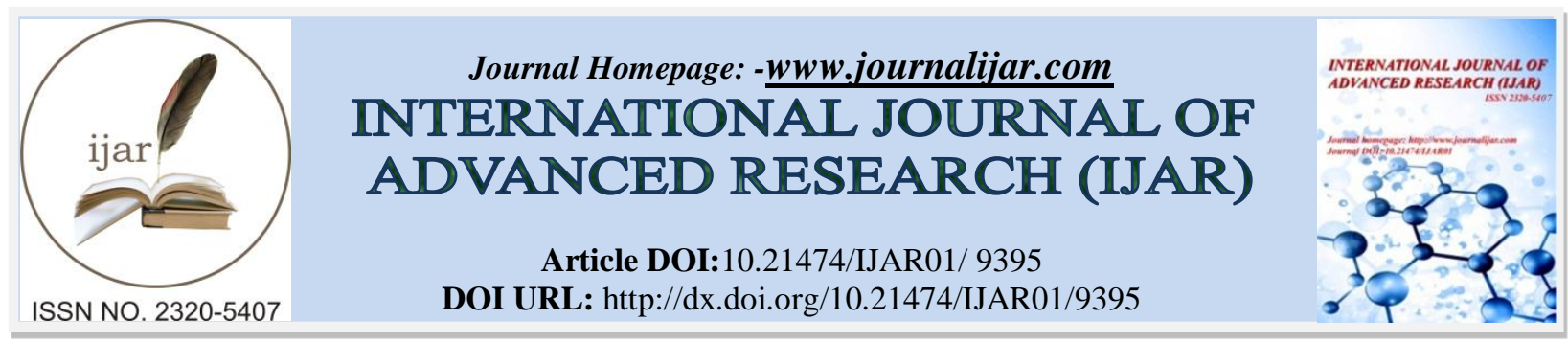

RESEARCH ARTICLE

\title{
LEAD POISONING IN CHILDREN: A DESCRIPTIVE STUDY OF HOSPITALIZED IRAQI CHILDREN WITH LEAD POISONING.
}

\author{
Azhar Muzhir Suhail and Mahjoob Al-Nidawi \\ Ministry of Health / Iraq-Baghdad
}

\section{Manuscript Info}

\section{Manuscript History}

Received: 17 May 2019

Final Accepted: 19 June 2019

Published: July 2019

Key words:-

Lead poisoning, Industrial environment and Inorganic lead.

\section{Abstract}

Background: Lead is one of the oldest perhaps most ubiquitous of neurotoxic substances although some of toxic effects of lead were known in earlier times.

Aim of study: To evaluate the extent of lead poisoning as a public health problem and to determine the main sources of lead in the environment the patients belong to \& the risk factors increasing the potential of poisoning in Iraqi children.

Material and Method: retrospective study on 56 cases of acute of lead poisoning had been the admitted to AL-MANSUR children teaching hospital during the period from March 1993 to March 2003. For children age range from 2 months to 7 years, 40 cases blow 2 years, 16 cases more than 2 years.

Results: It was found that 20 cases are females $(35.7 \%)$ and 36 cases are males $(64.2 \%)$. Regarding residency $45(80.3 \%)$ were living in urban areas, $11(19.6 \%)$ were living in rural areas. Positive family history was present in 16 cases $(28.5 \%) ; 10$ of them had affected sibling; 3 had parent affected and other relatives in 3 cases. From a total 56 cases, only 25 cases (44.6\%) were on breast feeding; 5 (8.9\%) on artificial feeding; 10 (17.8\%) on mixed feeding; $1628.5 \%)$ were on ordinary diet. History of pica is present in 27 cases $(48.25 \%)$, negative in 14 (25\%); unknown in 15 (26.87\%). Kohl application is used in 18 cases (46\%) out of 39 patients below 1 year of age; negative in 9 cases (23\%) unknown in 12 cases $(30.7 \%)$. The highest number of cases reported over the decade was on the year 1996 (14 cases). Most presenting sign is pallor 47 cases $(83.9 \%)$, most presenting symptoms is fit 18 cases (32\%). Commonest type of anemia is hypochromic microcytic in 19 cases (33.9\%). White line in X-ray of bones is positive in 24 cases from 35 cases $(68.5 \%)$. Urine $\delta$ ALA is positive in 24 cases from 35 cases $(86.5 \%)$. The mean value of $\delta$ ALA was 29.7. Blood punctate basophilia is present in 20 cases (35.7\%).

Conclusion: Lead poisoning continues to be a major public health problem with high mortality and long hospital stay. Children in the first 2 years of life are mostly affected, males are more than females.

Copy Right, IJAR, 2019,. All rights reserved. 


\section{Introduction:-}

Lead is a highly toxic metal and a very strong poison ${ }^{(1)}$. Elevated of lead may also be changes in red blood cells or dense line in the bones of children seen on x-rays ${ }^{(2)}$. The exposition to lead in the Antiquity is one of the first environmental health risks in the history of the mankind Lead has been widely used throughout history. Lead is mentioned in ancient Egyptian manuscripts ${ }^{(3)}$. Lead is one of the oldest known and most widely studied occupational and environmental poison. Despite intensive study, there is still debate about the toxic effects of lead, both from low-level exposure in the general population owing to environmental pollution and historic use of lead in paint and plumbing and from exposure in the occupational setting ${ }^{(4)}$. Inorganic lead salts are generally poorly soluble in aqueous solution. Dissolution of lead containing particulate depends on: particle size, pH \& presence of other dietary components as calcium \& iron. Phytates found in leafy green vegetables such as spinach may bind metals and increase their excretion. Inorganic lead salts are generally poorly soluble in aqueous solution. Dissolution of lead containing particulate depends on: particle size, $\mathrm{pH} \&$ presence of other dietary components as calcium \& iron ${ }^{(5)}$. Fat intake has been correlated directly with blood lead level in epidemiological studies. Most common pathway among children is through the mouth (pica \& fine dust from dirty hands and toys) ${ }^{(6)}$.

\section{Effect of lead on heme synthesis:}

Several enzymes involved in the synthesis of the heme and sensitive to inhibition by lead. The two most susceptible enzymes are ALAD and heme synthetase enzymes. Although clinical anemia occurs only after moderate exposure to lead, biochemical effects can be observed at lower levels ${ }^{(7)}$. So inhibition of ALAD or appearance in the urine of ALA and coproporpherin can be used as indicator of lead exposure. Other enzyme in heme synthesis chain that is severely damaged by lead is ferrochelatase which catalyzes the culminating step of heme synthesis. The insertion of iron into protoporphyrin IX ring. So result in accumulation of protoporphyrin in RBC. This because of its fluorescence and easily detected permits rapid and accurate measurement of erythrocyte protoporphyrin EP ${ }^{(8)}$.

\section{Subjects and Methods:}

This retrospective study to children admitted to Al-Mansour hospital from march 1993-march 2003 depending on the information reported in the case sheet and poisoning consultation center and also by contact family when it was possible.

During the period from March 1993 to March 2003 there is 56 case was admitted to Al-Mansour children teaching hospital with signs and symptoms suggestive and proved by lad investigation to be lead-intoxication; many of them were referred from other centers for further evaluation and treatment.

The variables for analysis in this study were include: age, sex, residence (rural or urban areas), soda-economic status, presence or history of pica, presence or history Al kohl application, type of feeding, family history of lead poisoning, locality. Signs which include (pallor, lethargy, pelging fontanel, come, ataxia, papilledema, short stature and gum lead line). Symptoms of (vomiting, seizures, lethargy, irritability constipation, abd. Pain, anorexia, relactant to feed). Type of anemia: hypochromic normocytic, hypochroimc, normchromic normocytic, nonmentioned, hemolytic anemia. Because blood lead level estimation was unavailable so we depend on special parameters of lead poisoning as $\delta$ ALA level in $\mathrm{mg}$ /creatinine level in grams in litre of urine. The normal value is 4.5 but maximum is 10 in adult. Patients included in this research were: (1) Patient having final result more than $10 \mathrm{mg}$ $\delta$ ALA per gm crealinine in urine. (2) Patient having their final results more than $4.5 \mathrm{mg} \delta \mathrm{ALA} / \mathrm{mg} \mathrm{creatinine}$ in urine and less than 10 with characteristic X.R. findings and characteristic CBP including basophilic stippling.

\section{The results:}

From a total 56 cases of acute lead poisoning studied in this work. Forty cases below 2 years of age. 16 cases more than 2 years of age. Twenty cases are female (35.7\%) and 36 cases are male (64.2\%). Male to female ratio of (1.8/1). 45 child were living in urban areas (80.3\%). Eleven child were living in rural areas (19.6\%). There is positive family history in 16 cases $(28.5 \%)$. Ten of them had affected sibling $(17.8 \%)$ and 3 of them had affected parent $(5.3 \%)$.

Three cases were other family member (5.3\%). Twenty five cases (44.6\%) were on breast feeding. Five cases $(8.9 \%)$ were on artificial feeding. Ten cases $(17.8 \%)$ were on mixed (breast and artificial feeding). Sixteen cases $(28.5 \%)$ were on ordinary diet. Pica was present in 27 cases (48.2\%) and it was absent in 14 cases $(25 \%)$ and in 15 cases (26.87\%) of unknown origin. Al kohl application: from 39 patient below one year of age is present in 18 cases (46\%) and absent in 9 cases (23\%). Unknown in 12 cases (30.7\%). The mean age of disease onset is 16.35 month. 
There is no significant difference in incidence of lead poisoning among variable educational status classes as shown in the following graphs $(1,2,3$ and 4$)$
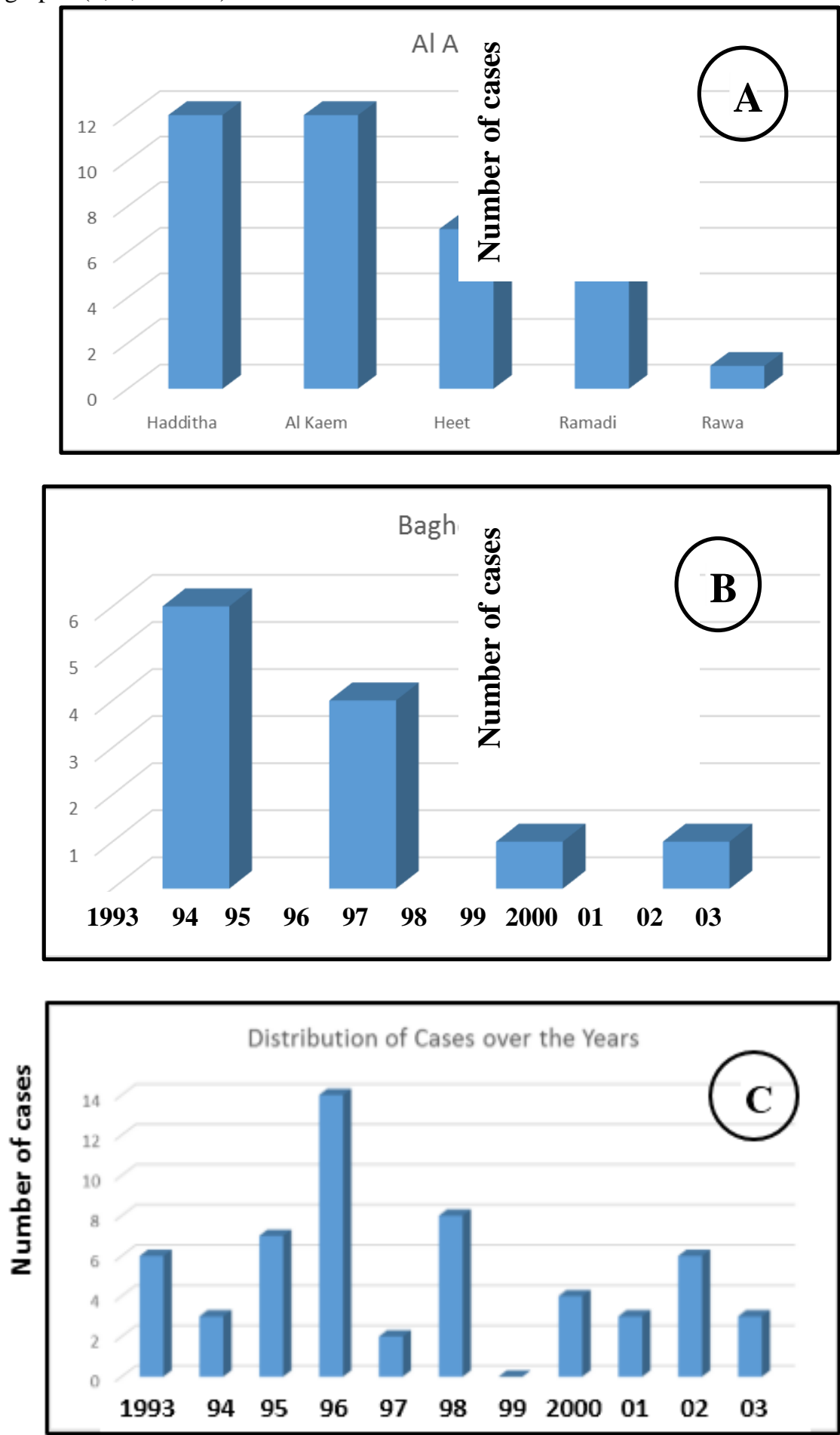

Figure 1:-A - the distribution of cases in ALANBAR. (B) - The distribution of cases in BAGHDAD. (C) - The distribution of over the YEARS. 

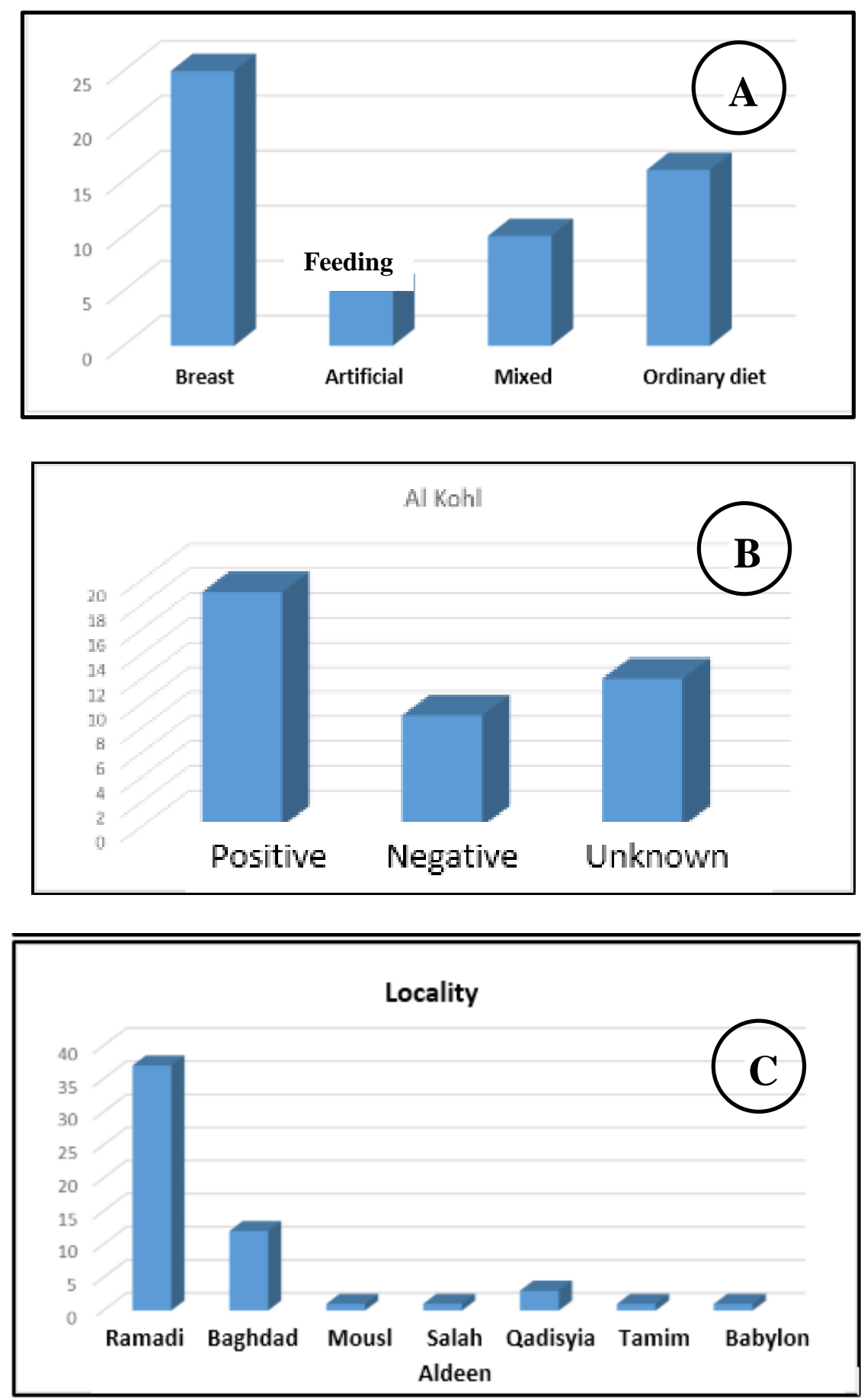

Figure 2:-show the distribution of lead poisoning according to (A) Al Kohl usage (B) Type of feeding and (C) locality of patients 


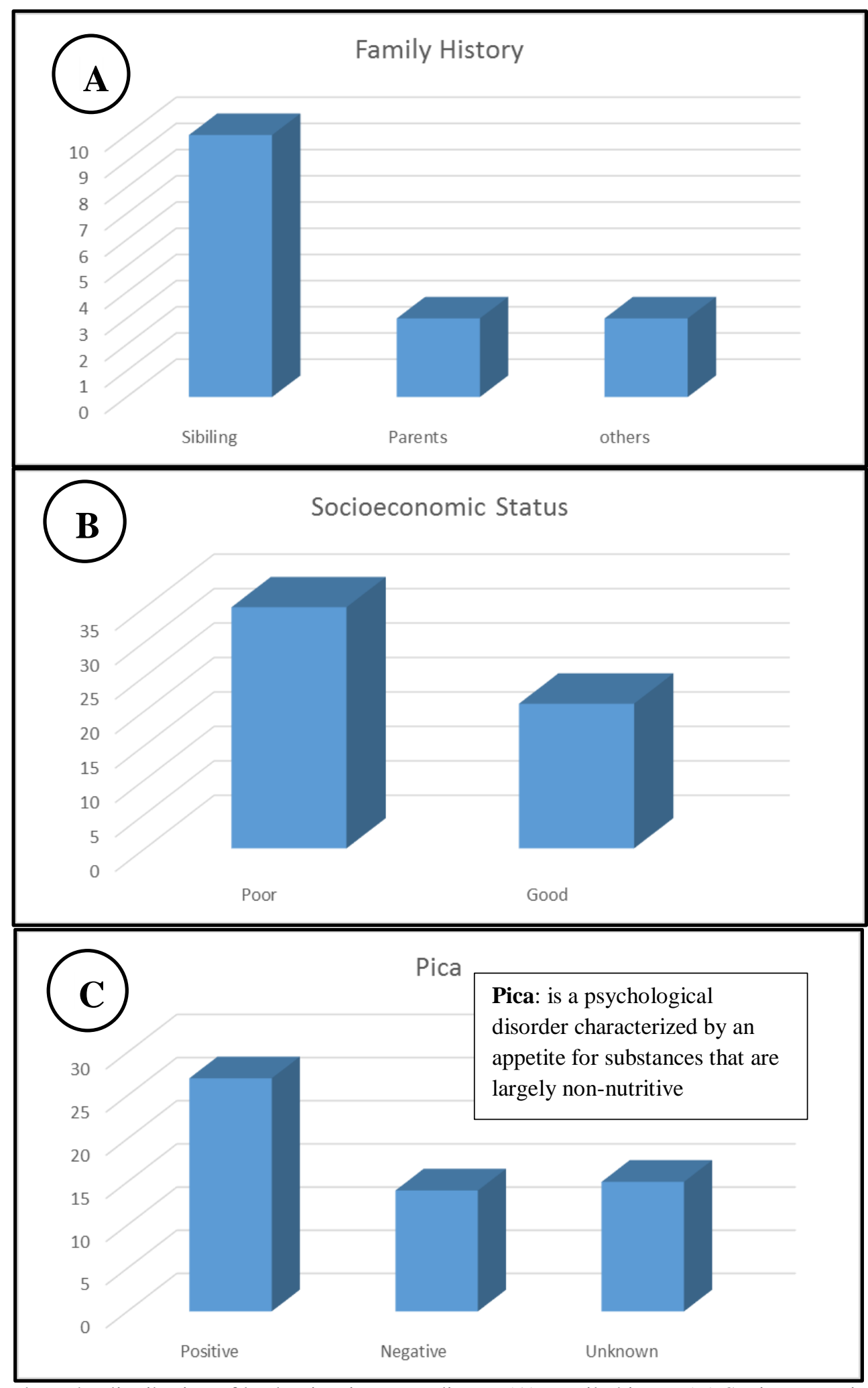

Figure 3:-show the distribution of lead poisoning according to (A) Family history (B) Socioeconomic status (C) Consumption of Pica 

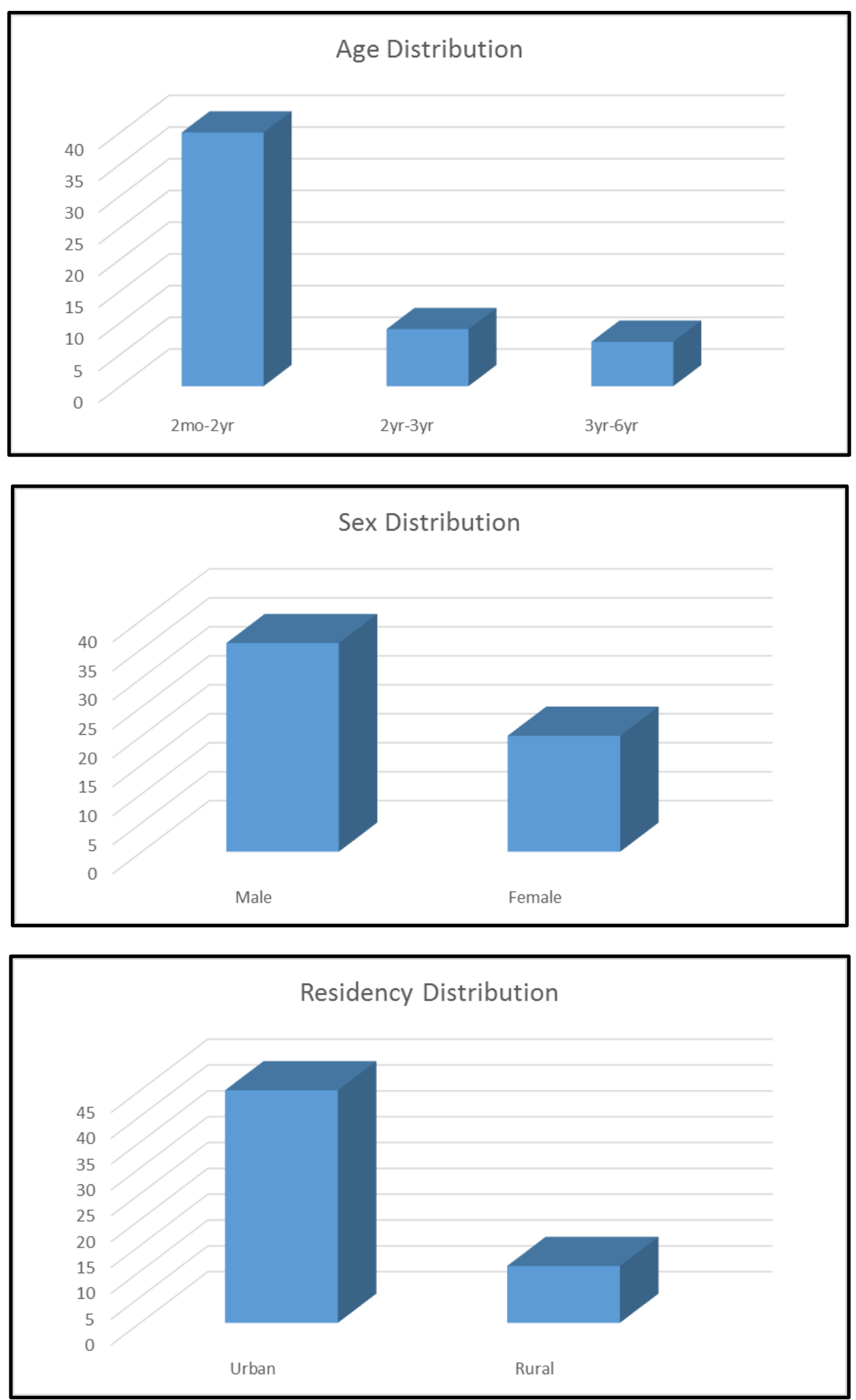

Figure 4:-It shows Age, Sex and Residency distribution of cases

Male to female ratio 1.8/1; this is nearly similar to another study $1.4 / 1$ done by Burke, E.C et al. with no biological base for this difference was found ${ }^{(9)}$. Chelation therapy in children is recommended when blood levels are greater than $40-45 \mu \mathrm{g} / \mathrm{dl}^{(\mathbf{1 0})}$. Chelation therapy is a medical procedure that involves the administration of chelating agents to 
remove heavy metals from the body ${ }^{(\mathbf{1 1})}$. It administered under very careful medical supervision due to various inherent risk ${ }^{(12)}$. This study was concluded the following points:

1. Lead poisoning continues to be a major public health problem with high mortality and long hospital stay. Children in the first 2 years of life are mostly affected, males are more than females.

2. Important risk factors are:

3. Living in endemic area (Al-Ramady Governate)

4. Al kohl and zaraqueen application to umbilical stump of neonate.

5. Living in urban areas, in houses painted more than 20 years ago.

6. Mal nutrition and poor socio-economic status.

7. High urinary $\delta$ ALA above $29.7 \mathrm{mg}$, more severe presentation.

8. Anemia is present in all patients and commonest type was hypochromic microcytic anemia. The most common presenting sign was pallor and the most common presenting symptom was convulsion and vomiting.

9. Commonest system involved in children with lead intoxication is CNS. While in adult is peripheral nervous system.

10. The whit metaphyseal line of long bones may be a sensitive test in adults even before the appearance of serious manifestation; but it is late manifestation in children.

11. Patient admission is beneficial.

12. Urinary $\delta$ ALA has a prognostic value.

\section{References:-}

1. Jacquelyn Cafasso and Daniel Murrel: lead poisoning: What is lead posoing health care on December 14, 2018

2. Dapul H., Laraque D.: Lead poisoning in children: Advances in Pediatric. (2014) 61 (1): P.p. 313-33.

3. Robles-Osorio ML, Sabath E. : Brief history of lead poisoning: from Egyptian civilization to the Renaissance. Rev Invest Clin. 2014; 66(1):88-91.

4. Jiri Patocka : Organic lead toxicology in Acta medica. 2008 51(4):209-13.

5. Ernest Hodgson E. and Levi, Patricia E, textbook of modern toxicology: 1997: P.p. 220

6. Morri Markowitz, Pediatrics in Review, vol. 21 No 10, October 2000 P.p. 327-359

7. Elizabeta Nemeth and Tomas Ganz: Anemia of Inflammation. Hematol Oncol Clin North Am. 2014 Aug; 28(4): 671-681.

8. Sergio Piomelli lead poisoning, Nelson's textbook of pediatrics $15^{\text {th }}$ edition (1996) P.p. 2010-2013.

9. Burke E.C et al, lead poisoning in children how serious? Minn. Med. J. 1992 Nov. 75(11):5.

10. What Do parents need to protect their children. CDC. 30 October 2012. Archived from the original on 9 October 2016

11. Aaseth, Jan; Crisponi, Guido; Anderson, Ole: Chelation therapy in The Treatment of Metal Intoxication. Academic Press. (2016) P. 388.

12. Atwood, K.C., IV; Woeker E.; Baratz, R.S.; Sampson, W.I.: Why the NH Trial to Assess Chelation Therapy (TACT) should be abandoned, (2008) Medscape Journal of Medicine: 10 (5): 115. 